\title{
В.С. ГРІНЧЕНКО
}

\section{ОЦІНКА ДОВЖИНИ СИСТЕМИ КОНТУРНОГО ЕКРАНУВАННЯ ПРИ ЗМЕНШЕННІ МАГНІТНОГО ПОЛЯ КАБЕЛЬНИХ ЛІНІЙ}

Розглянуто зменшення магнітного поля кабельної лінії електропередачі за допомогою системи контурного екранування. Отримано наближені аналітичні вирази для розрахунку комплексної амплітуди та діючого значення магнітної індукції в області екранування. Запропоновано прозору фізичну інтерпретацію отриманих співвідношень і параметру $\gamma$, який вони містять. Розглянуто граничний випадок $\gamma=1$, коли довжина системи контурного екранування набагато перевищує відстань від кабельної лінії до області екранування. Для випадку довільної довжини системи контурного екранування запропоновано функцію апроксимації залежності параметра $\gamma$ від відношення відстані між крайніми точками екранного контуру та областю екранування до відстані між центральним кабелем лінії електропередачі та границею області екранування. Для визначення довжини системи контурного екранування розв'язано обернену задачу. У результаті дано рекомендації щодо оцінки довжини системи контурного екранування, якщо відомо таке: гранично допустимий рівень магнітного поля, який має бути досягнуто у всій області екранування; величина струму в кабельній лінії та відстань між іії кабелями; амплітуда та початкова фаза струму в системі контурного екранування, а також відстань між її проводами, які розташовано паралельно кабельній лінії; довжина області екранування та її віддаленість від кабельної лінії.

Ключові слова: кабельна лінія, екранування, гранично допустимий рівень, магнітне поле, промислова частота.

\section{В.С. ГРИНЧЕНКО}

\section{ОЦЕНКА ДЛИНЫ СИСТЕМЫ КОНТУРНОГО ЭКРАНИРОВАНИЯ ПРИ УМЕНЬШЕНИИ МАГНИТНОГО ПОЛЯ КАБЕЛЬНЫХ ЛИНИЙ}

Рассмотрено уменьшение магнитного поля кабельной линии электропередачи при помощи системы контурного экранирования. Получены приближенные аналитические выражения для расчета комплексной амплитуды и действующего значения магнитной индукции в области экранирования. Дана прозрачная физическая интерпретация полученных соотношений и параметра $\gamma$, который они содержат. Рассмотрен предельный случай $\gamma=1$, когда длина системы контурного экранирования намного превосходит расстояние от кабельной линии до области экранирования. Для случая произвольной длины системы контурного экранирования предложена функция аппроксимации зависимости параметра $\gamma$ от отношения расстояния между крайними точками экранного контура и областью экранирования к расстоянию между центральным кабелем линии электропередачи и границей области экранирования. Для определения длины системы контурного экранирования решена обратная задача. В результате даны рекомендации по оценке длины системы контурного экранирования, если известно следующее: предельно допустимый уровень магнитного поля, который должен быть достигнут во всей области экранирования; величина тока в кабельной линии и расстояние между ее кабелями; амплитуда и начальная фаза тока в системе контурного экранирования, а также расстояние между ее проводами, которые расположены параллельно кабельной линии; длина области экранирования и ее удаленность от кабельной линии.

Ключевые слова: кабельная линия, экранирование, предельно допустимый уровень, магнитное поле, промышленная частота.

\section{V.S. GRINCHENKO}

\section{LENGTH ESTIMATION FOR LOOP SHIELDING SYSTEM WHEN DECREASING CABLE LINE MAGNETIC FIELD}

This paper deals with a mitigation of a cable line magnetic field by a loop shield. Approximate analytical expressions for a phasor and rms value of a magnetic flux density in a shielding area are developed. I give a clear physical interpretation for the obtained relations and the parameter $\gamma$ that they contain. The limiting case $\gamma=1$ is considered, when the loop shield length is much greater than the distance from the cable line to the shielding area. For the case of an arbitrary length of the loop shield, I propose a function to approximate the dependence of $\gamma$ on the ratio of the distance between the extreme points of the loop shield and the shielding area to the distance between the central cable of the power line and the shielding area boundary. To determine the loop shield length, the inverse problem is solved. As a result, I develop recommendations for estimating the loop shield length taking into account the following: the magnetic field reference level in the shielding area; the current in the cable line and the distance between its cables; the amplitude and the phase shift of the current in the loop shield, as well as the distance between its conductors, which are parallel to the cable line; the length of the shielding area and its distance from the cable line.

Keywords: cable line, shielding, reference level, magnetic field, power frequency.

Вступ. Найбільш доцільним засобом передачі електричної енергії в житлових зонах, особливо в разі щільної забудови, є підземні високовольтні кабельні лінії (КЛ). Це зумовлено тим, що згідно [1] ширина охоронної зони повітряних ліній електропередачі сягає десятків метрів.

Для прокладки високовольтних КЛ використовують одножильні кабелі 3 ізоляцією зі зшитого поліетилену. Нормативний документ [2] допускає прокладання кабелів як у горизонтальній площині, так i y вершинах трикутника. Прокладання кабелів «у площині» набуло широке розповсюдження, оскільки забезпечує більшу пропускну спроможність
КЛ, подальше підвищення якої досягається збільшенням відстані між кабелями. Проте магнітне поле (МП) КЛ із розташуванням кабелів «у площині» істотно перевищує МП при розташуванні кабелів «у трикутник» [3]. Оскільки в будівлях, що розташовуються поблизу трас КЛ, МП не повинно перевищувати гранично допустимий рівень $B_{0}=0,5$ мкТл [2], то виникає необхідність його екранування.

Традиційно для зменшення МП КЛ використовують електромагнітні та магнітні (магнітостатичні) екрани [4-6]. Проте на цей час найбільш перспективним засобом зменшення МП КЛ 
$\epsilon$ системи контурного екранування (СКЕ) [7-10]. Принцип дії СКЕ аналогічний до принципу дії електромагнітного екрана: первинне змінне МП КЛ створює змінний магнітний потік, що пронизує СКЕ, та відповідно до закону електромагнітної індукції в проводах СКЕ індукується електричний струм. Для підвищення ефективності екранування використовують СКЕ із різною кількістю контурів, варіюють їхню форму та орієнтацію в просторі, використовують допоміжні конденсатори та феромагнітні елементи. Так, в [10] запропоновано одноконтурний екран із несиметричним магнітним зв'язком, який забезпечує високу ефективність екранування та мінімізує тепловий вплив на КЛ, що дає змогу уникнути зниження пї пропускної спроможності.

Проте відомі дослідження обмежено аналізом екранованого МП у плоскопаралельному наближенні. Тобто вважається, що довжина СКЕ набагато перевищує відстань від КЛ до зони екранування. Тому питання визначення довжини СКЕ лишається недослідженим.

Метою даної роботи є оцінка довжини СКЕ, при якій в області екранування МП КЛ зменшується до гранично допустимого рівня.

Умовні позначення та використана система координат показані на рис. 1. Точка початку координат розташовується на висоті 0,5 м над умовним рівнем землі. Тоді згідно [2] МП КЛ нормується в площині $x O z$.

Силові кабелі пронумеровано латинськими літерами: $L$ - лівий, $C$ - центральний, $R$ - правий. Вони розташовані в площині $y=-h_{1}$. Відстань між сусідніми кабелями позначено $a_{1}$. Вважається, що КЛ працює в усталеному симетричному режимі, частота дорівнює промисловій 50 Гц, а струми КЛ утворюють пряму послідовність. Тоді комплексні амплітуди струмів у жилах визначаються у такий спосіб:

$$
\left\{\begin{array}{l}
\dot{I}_{L}=\sqrt{2} I e^{-j \cdot \frac{2 \pi}{3}}, \\
\dot{I}_{C}=\sqrt{2} I, \\
\dot{I}_{R}=\sqrt{2} I e^{j \cdot \frac{2 \pi}{3}},
\end{array}\right.
$$

де $I$ - діюче значення струму в жилах кабелів; $j$ уявна одиниця.

У цій роботі взято до уваги лише екранний контур без урахування інших елементів, які належать СКЕ. Контур розташовано в площині $y=-h_{2}$. Протяжні частини контуру паралельні КЛ. Довжина контуру $l_{2}$, його ширина - $2 a_{2}$, комплексна амплітуда струму в екранному контурі $-\dot{I}_{2}$.

На рис. 2,a показано розташування КЛ, екранного контуру СКЕ та області екранування в горизонтальній проекції. Довжину області екранування позначено $l$, відстань до КЛ - $b$. Різниця половин довжин екранного контуру та області екранування $c=\left(l_{2}-l\right) / 2$.

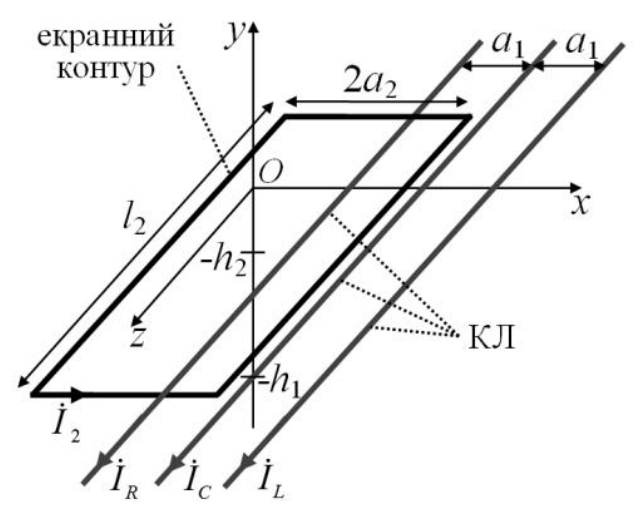

Рис. 1. Схема розташування КЛ та екранного контуру

Визначення МП. При аналізі МП системи «КЛ - СКЕ» зроблено низку спрощень:

a) Оскільки рівень МП в області екранування тим більший, чим ближче розташована точка спостереження до КЛ, то розглянуто МП лише у крайній точці Р області екранування.

б) В [11] показано, що МП системи струмів (1) при розташуванні проводів в одній площині еквівалентно МП прямого та оберненого проводів зі струмом $\dot{I}_{1}=j \cdot \sqrt{\frac{3}{2}} \cdot I . \quad$ Відповідно, КЛ замінено двома струмовими нитками, як показано на рис. 2,б.

в) Оскільки довжина поперечних ділянок СКЕ, які паралельні осі $x$, зазвичай набагато менша за довжину повздовжніх ділянок, що паралельні осі $z$, то при аналізі МП першими знехтувано.

2) Вважається, що кут огляду СКЕ із точки Р $\epsilon$ тупим. Тому повздовжні ділянки СКЕ змінено на напівнескінченні струмові нитки.

д) Вважається, що область екранування віддалено настільки, що можна нехтувати глибиною прокладки КЛ та СКЕ, тобто $h_{1}=h_{2}=0$. Отже, точка спостереження Р та струмові нитки, які показано на рис. $2, \sigma$, розташовано в одній площині.
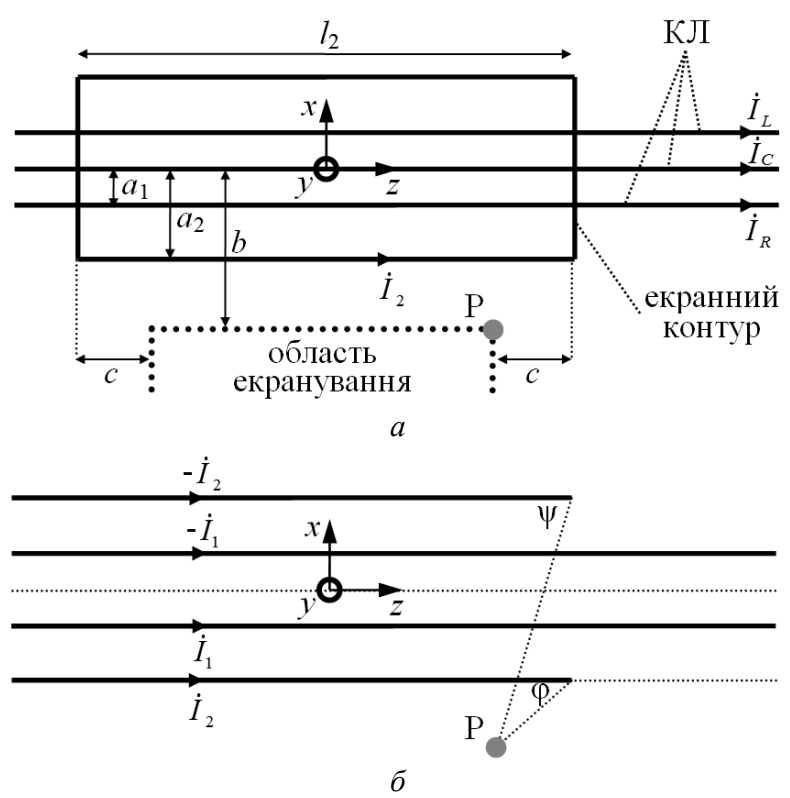

Рис. 2. Горизонтальна проекція КЛ та екранного контуру ( $a$ ) та вигляд спрощеної системи струмових ниток (б) 
Отже, враховуючи прийняті припущення, задачу зведено до розрахунку МП струмових ниток у точці спостереження $\mathrm{P}$ (рис. 2,б). Оскільки точка $\mathrm{P}$ та струмові нитки лежать в одній площині, то комплексна амплітуда магнітної індукції в точці Р має тільки одну ненульову $y$-компоненту. Для зручності розглядається мінус $y$-компонента магнітної індукції:

$$
\begin{aligned}
\dot{B}_{\mathrm{P}} & =\frac{\mu_{0}}{2 \pi} \frac{\dot{I}_{1}}{b-a_{1}}-\frac{\mu_{0}}{2 \pi} \frac{\dot{I}_{1}}{b+a_{1}}+ \\
& +\frac{\mu_{0}}{4 \pi} \frac{\dot{I}_{2}}{b-a_{2}}(1+\cos \varphi)-\frac{\mu_{0}}{4 \pi} \frac{\dot{I}_{2}}{b+a_{2}}(1+\cos \psi),
\end{aligned}
$$

де $\mu_{0}=4 \pi \cdot 10^{-7} \Gamma \mathrm{H} / \mathrm{M}-$ магнітна стала, а косинуси кутів $\varphi$ та $\psi$, які показано на рис. 2, очевидним способом виражаються через $a_{2}, b$ та $c$.

Праву частину отриманого співвідношення переписано в термінах безрозмірних змінних $\tilde{a}_{1}=a_{1} / b, \quad \tilde{a}_{2}=a_{2} / b, \quad \tilde{c}=c / b$ та розкладено в ряд в околиці $\tilde{a}_{1}=0, \tilde{a}_{2}=0$, лишаючи тільки лінійні члени. У результаті

$$
\dot{B}_{\mathrm{P}}=\frac{\mu_{0}}{2 \pi} \frac{\dot{I}_{1}}{b} \cdot\left\{2 \tilde{a}_{1}+\frac{\dot{I}_{2}}{\dot{I}_{1}} \frac{2 \cdot \tilde{c}+\tilde{c}^{3}+\left(1+\tilde{c}^{2}\right)^{3 / 2}}{\left(1+\tilde{c}^{2}\right)^{3 / 2}} \tilde{a}_{2}\right\} .
$$

Повертаючись до початкових розмірних змінних, отримано вираз для комплексної амплітуди магнітної індукції в точці Р:

$$
\dot{B}_{\mathrm{P}}=\frac{\mu_{0}}{\pi b^{2}} \cdot\left\{a_{1} \cdot \dot{I}_{1}+\gamma \cdot a_{2} \cdot \dot{I}_{2}\right\}
$$

де безрозмірний параметр

$$
\gamma=\frac{1}{2} \cdot\left(1+\frac{\frac{c}{b}}{\sqrt{1+\left(\frac{c}{b}\right)^{2}}} \cdot\left(1+\frac{1}{1+\left(\frac{c}{b}\right)^{2}}\right)\right)
$$

Вираз (2) має просту фізичну інтерпретацію, оскільки перший доданок його правої частини $€$ наближеним значенням величини МП КЛ, а другий доданок - МП СКЕ. Параметр $\gamma$ залежить від довжини СКЕ та визначає внесок її струмів у результуюче МП. Коли $c$ набагато більша за $b$, параметр $\gamma=1$, та, відповідно, співвідношення (2) описує МП системи нескінченних струмових ниток.

3 (2) випливає, що діюче значення магнітної індукції, що використовується при нормуванні МП, має вигляд

$$
B=\sqrt{\frac{\dot{B}_{\mathrm{P}} \cdot \dot{B}_{\mathrm{P}}^{*}}{2}}=\frac{\mu_{0}}{\sqrt{2} \pi b^{2}} \cdot\left\{\begin{array}{c}
a_{1}^{2} \dot{I}_{1} \dot{I}_{1}^{*}+\gamma^{2} \cdot a_{2}^{2} \dot{I}_{2} \dot{I}_{2}^{*}+\dot{I}^{*}+a_{1} a_{2}\left(\dot{I}_{1}^{*} \dot{I}_{2}+\dot{I}_{1} \dot{I}_{2}^{*}\right) \\
+\gamma
\end{array}\right\}^{\frac{1}{2}},
$$

де $\dot{B}_{\mathrm{P}}^{*}$ та $\dot{B}_{\mathrm{P}} \epsilon$ комплексно-спряженими.

Оцінка довжини СКЕ. Для визначення довжини CКЕ в ліву частину (4) покладено $B=B_{0}$, а отримане співвідношення розв'язано відносно $\gamma$. В результаті отримано таке:

$$
\gamma=-\frac{a_{1}}{a_{2}} \cdot \operatorname{Re} \frac{\dot{I}_{1}}{\dot{I}_{2}}-\sqrt{\left(\frac{a_{1}}{a_{2}} \cdot \operatorname{Im} \frac{\dot{I}_{1}}{\dot{I}_{2}}\right)^{2}+2 \cdot\left(\frac{\pi b^{2} B_{0}}{\mu_{0} a_{2} I_{2}}\right)^{2}},
$$

де $I_{2}$ - амплітуда струму в екранному контурі.

Параметр $\gamma$ визначає довжину $c$ крайової ділянки CКЕ. Зважаючи на поведінку $\gamma$ як функції змінної $c / b$, яка представлена на рис. 3 , запропоновано такий спосіб іiї апроксимації:

$$
\gamma=\left\{\begin{array}{cc}
\frac{1}{2}+\frac{5}{6} \cdot \frac{c}{b} & , \frac{c}{b}<\frac{3}{5}, \\
1, & \frac{c}{b} \geq \frac{3}{5} .
\end{array}\right.
$$

Найбільша розбіжність між точним (3) та наближеним (6) значеннями $\gamma$ спостерігається лише у відносно вузькому інтервалі поблизу $c / b=\sqrt{2}$.

Обертаючи (6), отримано таке:

$$
\frac{c}{b}=\left\{\begin{array}{cc}
\frac{3}{5} \cdot(2 \gamma-1) & , \quad \gamma<1, \\
\frac{3}{5} & , \quad \gamma \geq 1 .
\end{array}\right.
$$

Порівняльний аналіз результатів розрахунку МП за наближеним співвідношенням (4) i точними виразами, які описують МП системи «КЛ - СКЕ» без використання спрощень $a$ - $\partial$ та не приводяться в цій роботі через їхню громіздкість, показує, що отримане за допомогою (7) значення $c$ необхідно помножити на корегувальний множник 1,5. Тобто проекція СКЕ на область екранування виступає за іiі границю (у напрямку осі $z$ ) на $1,5 \cdot c$ з кожного кінця.

Отже, для оцінки довжини СКЕ при зменшенні МП КЛ із прокладкою кабелів «у площині» необхідно:

- визначити довжину $l$ області екранування;

- визначити відстань $a_{1}$ між сусідніми кабелями та діюче значення струму $I$ у КЛ;

- визначити напіввідстань $a_{2}$ між проводами СКЕ та комплексну амплітуду струму $\dot{I}_{2}$ у їі проводах;

- визначити відстань $b$ від центрального кабелю КЛ до границі області екранування, що розташована всередині будинку на відстані 0,5 м від стіни;

- визначити гранично допустимий рівень магнітної індукції $B_{0}$ за допомогою нормативних документів;

- розрахувати значення параметра $\gamma$ за допомогою (5), де $\dot{I}_{1} \approx j \cdot 1,22 \cdot I$.

- визначити с за допомогою (7).

Нарешті, загальна довжина СКЕ дорівнює $l+3 \cdot c$.

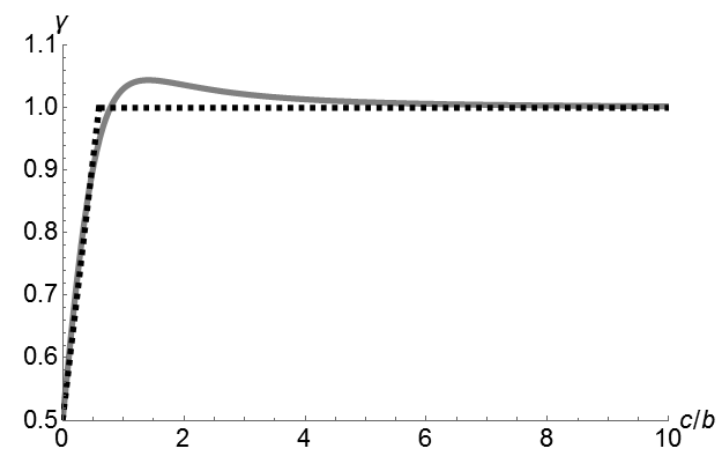

Рис. 3. Графік залежності параметра $\gamma$ від відношення розмірів $c / b$ (суцільна крива) та іiї апроксимація (пунктирна) 


\section{Висновки.}

1. У роботі отримано наближені аналітичні вирази для комплексної амплітуди та діючого значення магнітної індукції в області екранування, які можуть застосовуватися для оцінки рівня магнітного поля кабельної лінії при використанні систем контурного екранування.

2. Розроблено рекомендації для оцінки довжини систем контурного екранування, при якій магнітне поле, утворене кабельною лінією електропередачі, буде зменшено в області екранування до гранично допустимого рівня.

\section{Список літератури}

1. Постанова Кабінету Міністрів України від 4 березня 1997 p № 209 «Про затвердження Правил охорони електричних мереж» у редакції від 5 квітня 2017 p.

2. Правила улаштування електроустановок. - К: Міненерговугілля України, 2017. - 617 с.

3. Магнитное поле линий электропередачи и методы его снижения до безопасного уровня / В.Ю. Розов, С.Ю. Реуцкий, Д.Е. Пелевин, О.Ю. Пилюгина // Технічна електродинаміка. - 2013. - № 2. - С. 3-9.

4. Salinas E. Conductive and ferromagnetic screening of $50 \mathrm{~Hz}$ magnetic fields from a three-phase system of busbars / E. Salinas // Journal of Magnetism and Magnetic Materials. - 2001. - Vol. 226230. - Pp. 1239-1241.

5. Electromagnetic shielding of high-voltage cables / M. De Wulf, P. Wouters, P. Sergeant, L. Dupre, E. Hoferlin, S. Jacobs, P. Harlet // Journal of Magnetism and Magnetic Materials. - 2007. - Vol. 316 - Pp. e908-e911.

6. Highly efficient shielding of high-voltage underground power lines by pure iron screens / M. Zucca, G. Lorusso, F. Fiorillo, P.E. Roccato, M. Annibale // Journal of Magnetism and Magnetic Materials. - 2008. - Vol. 320. - Pp. e1065-e1069.

7. Magnetic shielding solutions for the junction zone of high voltage underground power lines / A. Canova, D. Bavastro, F. Freschi, L. Giaccone, M. Repetto // Electric Power Systems Research. - 2012. - Vol. 89. - Pp. 109-115.

8. del Pino-López J.C. The effectiveness of compensated passive loops for mitigating underground power cable magnetic fields / J.C. del Pino-López, P. Cruz-Romero // IEEE Transactions on Power Delivery. - 2011. - Vol. 26, no. 2 - Pp. 674-683.

9. Maioli P. Passive loops technique for electromagnetic fields mitigation: applications and theoretical considerations / P. Maioli, E. Zaccone // Jicable International Conference on Insulated Power Cables. - 2007. - Pp. 231-236.

10. Эффективное контурное экранирование магнитного поля трехфазных кабельных линий при ограниченном тепловом воздействии на силовые кабели / В.Ю. Розов, В.С. Гринченко,
А.В. Ерисов, П.Н. Добродеев // Електротехніка Електромеханіка. - 2019. - № 6. - С. 50-54.

11. Walling R.A. Series-capacitor compensated shield scheme for enhanced mitigation of transmission line magnetic fields / R.A Walling, J.J. Paserba, C.W. Burns // IEEE Transactions on Power Delivery. - 1993. - Vol. 8, no. 1. - Pp. 461-469.

\section{References (transliterated)}

1. Decree of the Cabinet of Ministries of Ukraine dated March 4, 1997 No. 209 "About the statement of Rules of protection of electric networks": Edition on April 5, 2017. (Ukr).

2. Pravyla ulashtuvannja elektroustanovok [Rules of arrangement of electrical installations]. Kyiv, Minenergovugillja Ukrai'ny, 2017. 617 p. (Ukr).

3. Rozov V.Yu., Reutskii S.Yu., Pelevin D.E., Piliugina O.Yu. Magnitnoe pole linii elektroperedachi i metody ego snizheniia do bezopasnogo urovnia [The magnetic field of power transmission lines and the methods of its mitigation to a safe level]. Tekhnichna elektrodynamika. 2013, no. 2, pp. 3-9. (Rus).

4. Salinas E. Conductive and ferromagnetic screening of $50 \mathrm{~Hz}$ magnetic fields from a three-phase system of busbars. Journal of Magnetism and Magnetic Materials. 2001, vol. 226-230, pp. 12391241.

5. De Wulf M., Wouters P., Sergeant P., Dupre L., Hoferlin E., Jacobs S., Harlet P. Electromagnetic shielding of high-voltage cables. Journal of Magnetism and Magnetic Materials. 2007, vol. 316, pp. e908-e911.

6. Zucca M., Lorusso G., Fiorillo F., Roccato P.E., Annibale M. Highly efficient shielding of high-voltage underground power lines by pure iron screens. Journal of Magnetism and Magnetic Materials. 2008, vol. 320, pp. e1065-e1069.

7. Canova A., Bavastro D., Freschi F., Giaccone L., Repetto M. Magnetic shielding solutions for the junction zone of high voltage underground power lines. Electric Power Systems Research. 2012, vol. 89, pp. 109-115.

8. del Pino-López J.C., Cruz-Romero P. The effectiveness of compensated passive loops for mitigating underground power cable magnetic fields. IEEE Transactions on Power Delivery. 2011, vol. 26, no. 2, pp. 674-683

9. Maioli P., Zaccone E. Passive loops technique for electromagnetic fields mitigation: applications and theoretical considerations. Jicable International Conference on Insulated Power Cables. 2007, pp. 231-236.

10. Rozov V.Yu, Grinchenko V.S., Yerisov A.V., Dobrodeyev P.N. Efficient shielding of three-phase cable line magnetic field by passive loop under limited thermal effect on power cables. Electrical Engineering \& Electromechanics. 2019, no. 6, pp. 50-54.

11. Walling R.A., Paserba J.J., Burns C.W. Series-capacitor compensated shield scheme for enhanced mitigation of transmission line magnetic fields. IEEE Transactions on Power Delivery. 1993, vol. 8, no. 1, pp. 461-469.

Поступила (received) 01.10.2020

\section{Відомості про автора / Сведения про автора / About the author}

Грінченко Володимир Серzійович (Гринченко Владимир Серzеевич, Grinchenko Volodymyr Serhiiovych) - Державна установа «Інститут технічних проблем магнетизму Національної академії наук України», кандидат технічних наук, заступник директора з наукової роботи; м. Харків, Україна; е-mail: vsgrinchenko@ gmail.com 